\title{
Belphégor
}

\section{Regions, Maps, Readers: Theorizing Middlebrow Geography}

\section{Kristin Bluemel}

\section{(2) OpenEdition}

1 Journals

\section{Electronic version}

URL: http://journals.openedition.org/belphegor/948

DOI: 10.4000/belphegor.948

ISSN: 1499-7185

\section{Publisher}

LPCM

\section{Electronic reference}

Kristin Bluemel, « Regions, Maps, Readers: Theorizing Middlebrow Geography », Belphégor [Online], 15-2 | 2017, Online since 19 November 2017, connection on 30 April 2019. URL : http:// journals.openedition.org/belphegor/948; DOI : 10.4000/belphegor.948

This text was automatically generated on 30 April 2019.

\section{(c) (i) (9)}

Belphégor est mis à disposition selon les termes de la Licence Creative Commons Attribution - Pas d'Utilisation Commerciale - Pas de Modification 4.0 International. 


\title{
Regions, Maps, Readers: Theorizing Middlebrow Geography
}

\author{
Kristin Bluemel
}

1 To put a city in a book, to put the world on one sheet of paper - maps are the most condensed humanized spaces of all. . . . They make the landscape fit indoors, make us masters of sights we can't see and spaces we can't cover.

Robert Harbison, Foreword to Eccentric Spaces

2 The question "What is middlebrow fiction?' cannot be separated from the question "Where is middlebrow fiction?" To date, the fledging field of middlebrow studies has been defined by scholarship on media and culture in two regions, America and Britain. To conceptualize middlebrow beyond anglophone cultures, to think in terms of European middlebrow, for example, assumes that differences of geography organize other kinds of differences germane to study of cultural hierarchies. ${ }^{1}$ This paper approaches the problem of conceptualizing middlebrow fiction both in and beyond anglophone cultures by way of the maps that often illustrate books designated middlebrow. Maps are simply representations of things in space, ${ }^{2}$ and maps printed in fictions, particularly if they are maps of imaginary geographies, prompt readers to receive and imagine those fictions in graphic and visual terms that are similar, if not identical, to the literary and verbal terms critics have used to define and value middlebrow books. ${ }^{3}$ A shortlist of those terms would include words like immersive, page-turning, domestic, nostalgic, feminine, cosy, consensual, conservative, charming, child-like, and visual. ${ }^{4}$ Based on a case study of endpaper maps in an interwar English novel, Francis Brett Young's Portrait of a Village (1937), and the very similar endpaper maps in an interwar English story collection for children, Winnie the Pooh (1926), this paper argues that endpaper maps in fictional texts contribute towards those fictions' designation as middlebrow; that attention to the materials and material cultures of the book can help us discover and understand the peculiar association between tangible, textual maps and intangible middlebrow status; and more generally, that incorporation of visual forms and spatial representation within narratives published in clothbound books will diminish that narrative's cultural prestige in the literary field, excluding it from highbrow status even as its endpapers and cloth 
covers signal its aspirations to cultural significance and elevate it above the lowbrow illustrated papers that the vast new public of readers enjoyed. ${ }^{5}$

3 Erica Brown and Mary Grover are right to insist in their study of the Anglo-American battle of the brows that there was no 'emerging [middlebrow] literary form in the 1920s' (8), but it is also right to insist on the presence, at this period, of textual materials and paratextual forms, including endpaper maps, that invite and perhaps predict designation of middlebrow status. This paper argues that in addition to critics' attention to the languages, economics, and politics of Anglo-American middlebrow fiction, it is important for scholars of every middlebrow geography to attend to the material conditions of book production and consumption. What kinds of illustrations, papers, typeface, bindings, endpapers, and designs, conveyed through what kinds of varied artistic, industrial, and commercial processes, are required for consumers in diverse regions to behold an object that they recognize as a middlebrow book? How are these materials and processes distinguished by region and more importantly, how do these materials and processes themselves produce ideologies of region? Endpaper maps of an imagined place help us answer these questions.

\section{Endpaper Maps}

Endpapers are found only in cloth bound or hardcover books. They serve a practical function of hiding the glued down edges of the cover fabric and the symbolic function of signaling to readers that they are reading a 'good book,' one that aspires to a cultural status above generic, mass market, 'lowbrow' publications. Those who treasure books as aesthetic objects value endpapers for their weight, color, and design and their relation to other materials such as ink, paper, and typeface, as well as their relation to the book's story or subject. When a publisher commissions an artist to create a design for endpapers, something special is going on. The endpapers are proclaiming their status as art object, are asking us to notice and read them as we would a picture. Rarely do endpapers have lines of type, so rarely do we read them as we read a page of text. This is not due to cost, but rather is related to function. Endpapers are a kind of gateway, transitioning readers from binding to typed text as they enter and exit a book. Speaking of endpapers and books this way, as gateways and as things with entries and exits, highlights the slippage of geographical metaphor that makes endpapers with maps seem simply a more explicit or felicitous instance of a general condition. Metaphorically speaking, endpapers are always maps. Most noticeably in the case of fiction, endpapers signal or guide readers' shifts from the world of felt material objects and time-the outside reality of readers' physical encounter with a book-to the immaterial world of the imagination and suspended or elastic time-the inside reality of readers' encounters with story or subject.

5 Casey N. Cep notes in her article 'The Allure of the Map,' published in that most middlebrow of American periodicals, The New Yorker, that 'Genre fiction [adventure, fantasy, science fiction] often involves cartographic illustration, but so, too, do highly regionalist works'. She cites as evidence of the special affinity between maps and regional fiction Sherwood Anderson's commissioning of a map for Winesburg, Ohio, Henry David Thoreau's surveying of Walden Pond for a map he included in Walden, and William Faulkner's creation of his own map of Yoknapatawpha County for Absalom, Absalom!. Cep reminds us that Faulkner revised his map for The Portable Faulkner, 'going so far as to call himself 'sole owner and proprietor,' and adding a note: 'Surveyed \& mapped for this 
volume by William Faulkner". This is a singular instance of a literary critic endorsing a highbrow or modernist writer's professed fascination with maps under the banner of the regional novel. The middlebrow stature of Francis Brett Young is more typical of writers classed among the regionalists [Figure 1].Young was a retired country doctor who had spent most of his life in the region between Birmingham and the Clent Hills of Wales. He had achieved fame and fortune for his fictions about characters in the rugged midlands landscapes of Worcestershire who were very much like the patients he had treated during his years working as a physician. By the late 1930s, the period in which Heinemann commissioned him to write Portrait of a Village, he had abandoned his earlier commitment to writing fictions that challenged stereotypes of rural and regional life and was writing instead predictable, blandly reassuring sketches of country folk. As a result, Young became one of England's most successful novelists of rural England at precisely the same time that middlebrow as a term entered English cultural debate. Here, at the conjunction of rural regionalism and illustrated realism, regional and middlebrow fictions are essentially the same thing, valued in essentially the same way.



Figure 1: Portrait of Francis Brett Young, n.d. Source: http://www.fbysociety.co.uk/images/port4.jpg. Accessed 1 December 2015.

To make this claim is not to suggest that Young identified himself as a middlebrow novelist, or that he was described this way in the press. Nor is it to suggest that his literary productions are less valuable than those of writers designated modernist or less culturally powerful than those of writers designated lowbrow. Here the term middlebrow functions descriptively, not pejoratively, as a shorthand term that condenses and contains within it the phrase 'literature that would, in the interwar period, have been designated middlebrow by dominant critics' or 'readers who would, in the interwar period, have been designated middlebrow by dominant critics.' 
7 Any reader would find upon opening up the covers of Portrait of a Village an endpaper map of an imaginary village in England called Monk's Norton [Figure 2]. Experienced map readers will find in it all the conventional signs, symbols, and functions of a real map. It represents or reproduces landscape and human geography, its representations are contained within a border, and like a real map, it conforms to conventional associations of north at the top of the page, south at the bottom, east at the right and west at the left. As is customary, it requires the map reader to abandon a human perspective and look down on a landscape in a way that was, at the time this map was published, familiar only to birds or airmen. This pen and ink map by a young and very talented English wood engraver named Joan Hassall joins thirty of her wood engraved illustrations printed in the interior pages of the book in providing a spatial register against which readers can measure the narrative's verbal, and thus linear and temporal, narrative. Hassall's endpaper maps of Monk's Norton raise questions about relations between books designated middlebrow and those designated children's, for they bear a striking similarity to the much more famous endpaper maps by E. H. Shepard of The Hundred Acre Wood that decorate the inside covers of A. A. Milne's pastoral fantasy, Winnie the Pooh [Figure 3] . Suddenly two utterly disparate books, one categorized as a work of regional realism for adults, the other as an interwar fantasy for children, appear to share formal elements and be embarked upon a similar cultural project of framing pastoral fictions with geographic representations.

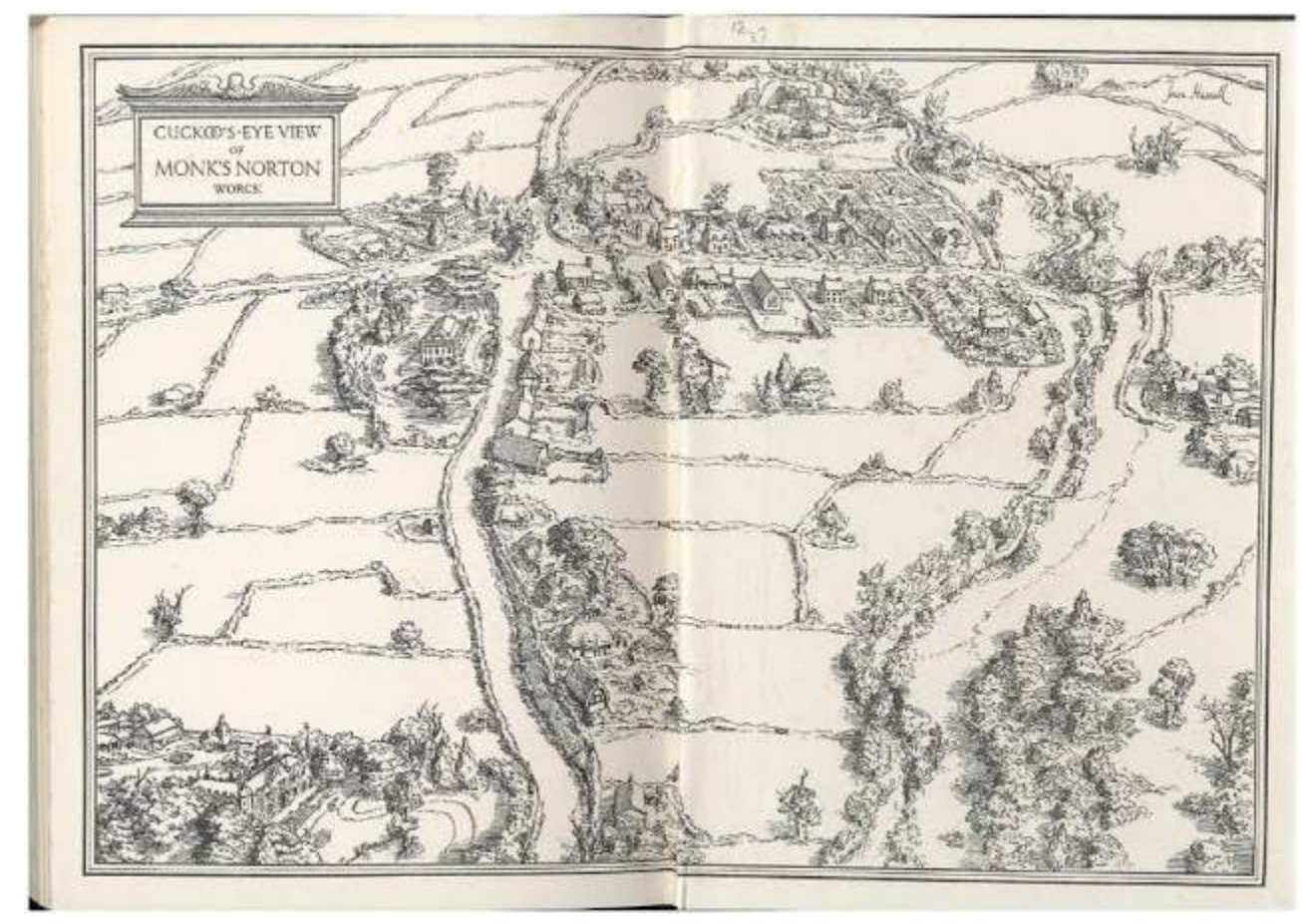

Figure 2: Joan Hassall's pen and ink endpaper map of Monk's Norton in Francis Brett Young's Portrait of a Village. Source: http://2.bp.blogspot.com/_JjoC7eqPOTQ/TD4g6eloVNI/ AAAAAAAAAOY/7vhBZh_0ZXg/s640/monks-norton.jpg. Accessed 1 December 2015. 


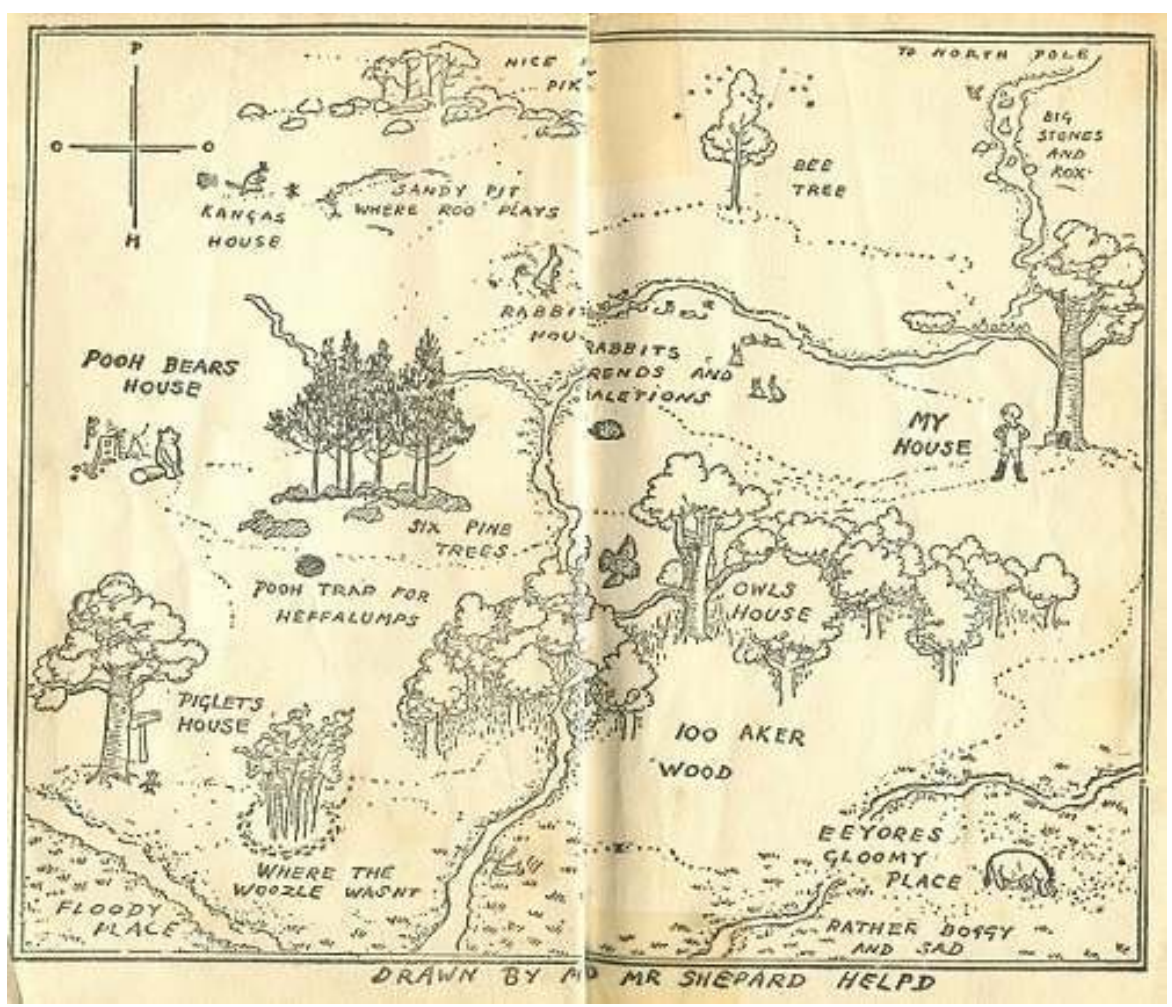

Figure 3: E. H. Shepard's pen and ink endpaper map of The Hundred Acre Wood in A. A. Milne's Winniethe-Pooh. Source: http://www.personal.psu.edu/users/j/m/jmc82/MilneMap.jpg. Accessed 1 December 2015.

The formal similarities between Hassall's and Shepard's endpaper maps support claims that there are unique parallels between the ways middlebrow and children's literature studies have been theorized. ${ }^{6}$ In what follows, study of middlebrow books is also study of regional and children's books. While it is obvious that not all literature labelled regional is also labelled middlebrow, any more than all literature aimed at children is necessarily 'middlebrow', the categories certainly intersect. Most interwar English regional, pastoral literature, published like Portrait of a Village between cloth covers and with decorated bindings and 'artistic' illustrations, belongs to the field of middlebrow. Most Golden Age or 'classic' English children's, pastoral literature, published like Winnie the Pooh between cloth covers and with decorated bindings and artistic illustrations, can equally be designated middlebrow. The critical method that bridges these typically divided literary categories emerges out of comparative close readings of the visual forms of literary maps and the verbal spaces 'inside' the books they adorn and between the visual forms of literary maps and the rural spaces 'outside' the books they adorn. Hassall's and Shepherd's endpaper maps launch and sustain this case study: they serve as guides to metaphor and history, leading readers to contemplate a contradictory but dynamic experience of rural modernity associated with the geography of the English countryside and articulated in its regional literature.

\section{Map Forms}

The first thing readers should notice if they compare the endpaper maps of Monks Norton and The Hundred Acre Wood is a double border. Whether in Hassall's or Shepard's 
map, we're in a circumscribed territory, a world contained neatly by straight lines and right angles. Both Hassall's and Shephard's maps also share a mapper's perspective on the fictional territory from somewhere up high. ${ }^{7}$ Both feature long rivers and roads that suggest movement and flow, in contrast to the confining border. This too is like a real map. But now consider the trees. The trees on these maps are so prominent that they seem heroic, even mythical. Reading the trees as components in the maps' language of rhetorical images we are reminded that the maps are indeed interpretive as well as geographical guides to the contents of the narratives. Readers can assume from Hassall's and Shepherd's endpapers, for example, that any story of culture is also very much a story of nature. Within the authors' territories of dreams, the mature trees signify the passing of time, or at least passing of past time. As is the nature of maps, pictures, and photographs, time is frozen along with space. Just as the trees on the illustrators' maps will grow no more, the maps themselves will never go out of date. They are always maps of lost territory, here the pastoral territory of childhood and the territory of idealized village England. It is no coincidence that these two territories look very much alike and were imagined and popularized at the same time middlebrow fiction became a public concern. The pressures of modernity, realized most acutely in the mechanized horrors of World War I, produced in adults intense yearnings for the places and times of peace; images of the countryside (a lost geography) and images of childhood (lost time) gave these yearnings tangible form.

The symbolic conflation of rural place and childhood time is more prevalent in texts published during the crisis years of urbanization and modern war because, in Susan Honeyman's words, writers, and readers responded to fragmentation and social isolation with a desire for 'totalizing space'. Literary maps in interwar fictions can be understood as effects and representations of the 'totalizing spaces' demanded by modernity. Honeyman is interested in the implications of a futile adult 'grasping' after the lost territories of childhood for critical understanding of the 'friendly spaces'-gardens, maps, and pictures -of children's literature, but scholars of middlebrow may also find explanation in her account for the appeal of maps in adult fictions of the interwar years. They 'bring fictional worlds closer while explaining their inaccessibility' (Honeyman).

\section{Children's Literature Scholars Think about Maps}

11 Many literature and history scholars have written about England's interwar fascination with rural places, but children's literature scholars have most consistently examined the way those places are imagined on literary maps. This is because pastoral place and mapped image appear so often in classic English children's literature whether it be Robert Louis Stevenson's map in Treasure Island [Figure 4], E. H Shepherd's maps in the Wind in the Willows and Winnie the Pooh, Arthur Ransome's map in Swallows and Amazons [Figure 5], or J. R. R. Tolkien's maps in The Hobbit [Figure 6]. Puzzling over these maps, the prominent children's literature scholar Peter Hunt argues that they are linked in a fundamental way to the centuries-long tradition of English fantasy writing that associates home with 'an unspoiled, idyllic, rural England-one which never really existed' (11-12). He says this idyll came, in time, to be located vaguely in the period between the wars, or before 1914' and in a space vaguely imagined as congruent with the area of the Thames valley or the so-called 'shires' (12). Thus literary maps are records of peculiar forces of history, of specific fantasies of nation and landscape consolidated in the interwar period, 
and records of timelessness, of fantasies of Englishness floating above a Neverland. Anthony Pavlik formulates this paradox somewhat differently, observing 'if a map is to be at all legible, it must of necessity mislead.' Describing endpaper maps as 'a subjectively descriptive system masquerading as objective truth' (32), he insists that 'the space of the map is always more than what is contained within its arbitrary borders' (37). In other words, he argues that the space of the map is the space outside the map. What's missing from Pavlik's intelligent theorizing is recognition that endpaper maps require a global theory of cultural production, one that can explain meaning and effects of maps in individual texts written for children or adults, and facilitate connections and comparisons between groups of texts (i.e. Anglo-American, European) sharing the characteristic forms of endpaper maps.

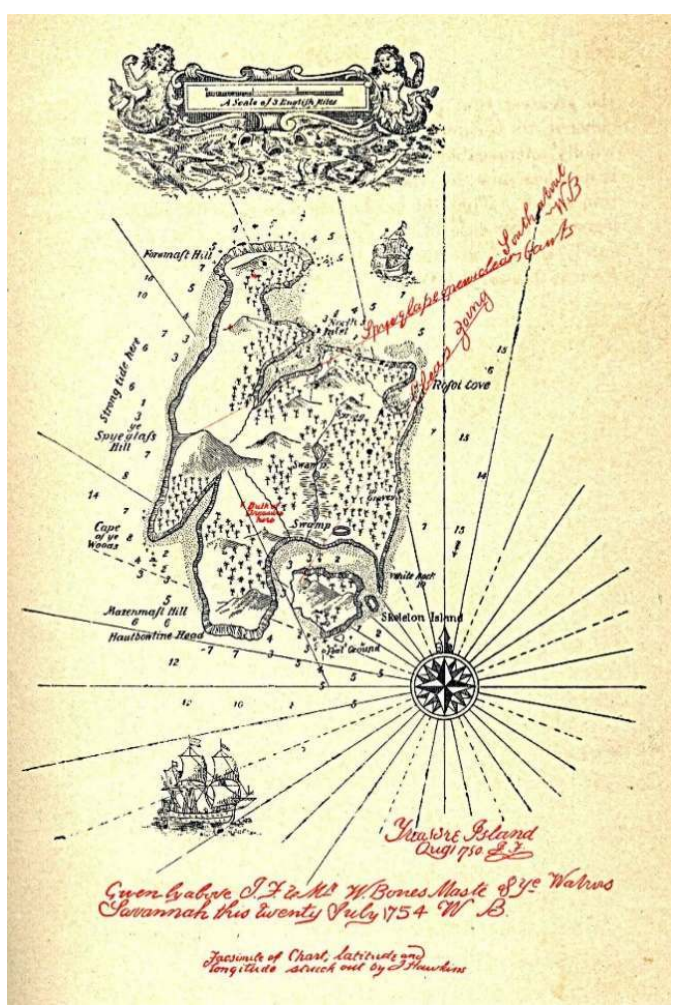

Figure 4: Robert Louis Stevenson's map of Treasure Island in his 1883 novel by that name. Source: http://www.kellscraft.com/maptreasisle.JPG. Accessed 1 December 2015. 


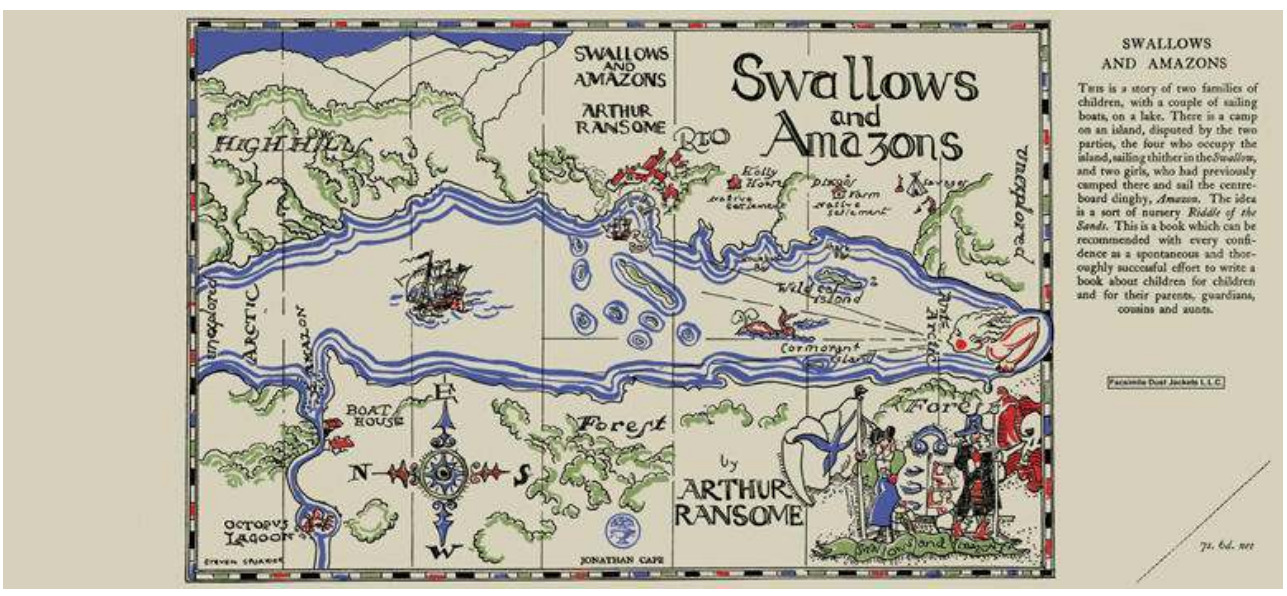

Figure 5: Steven Spurrier's dustjacket map of a fictionalized Lake District in Arthur Ransome's Swallows and Amazons (1930). Source: http://www.facsimiledustjackets.com/pictures/7007.jpg. Accessed 1 December 2015.



Figure 6: J. R. R. Tolkien's endpapers of "Thror's map," The Hobbit (1937). Source: http:// www.nicholastam.ca/wp-content/uploads/2011/04/thrors-map-endleaf.jpg. Accessed 1 December 2015.

\section{Geographers Think about Maps}

12 The epigraph framing this paper comes from Robert Harbison's book, Eccentric Spaces, and shows how some geographers have brought all the romance and sensibility of literature into their discussions of maps in order to advance a global theory of map form and function. In an influential article on 'Maps, Knowledge, and Power' (1988), geographer J. B. Harley defines maps as 'a kind of language' (278) or 'value-laden [and] . . . refracted images contributing to dialogue in a socially constructed world' (278). They are also a 
'class of rhetorical images' that are 'bound by rules which govern their codes and modes of social production, exchange, and use' (279). Viewing maps as value-laden, rhetorical images and as a kind of language or discourse with historically imbedded codes, Harley seeks to advance a larger project of understanding what Carl Sauer calls 'the eloquence of maps' (qtd. in Harley, 277).

13 Eloquence, rhetoric, and lies: these three things preoccupy scholars of literature and scholars of maps. Today most geographers agree that all maps lie, or, to quote Denis Wood, that 'all maps incorporate assumptions and conventions of the society and the individuals who create them'. Not too long before Wood's article was published, scholarly and popular map readers assumed that good maps were those that were self-evidently true because they were accurate, objective, literal, and scientific (Harley 278). A bad map was a map that could not bring its users to what geographers would describe as 'agreement about referentiality between geospace and textual spaces' (Piatti et al 182). In other words, a bad map for cartographers was a map that assumed the proportions of fiction. Joan Hassall's map or E. H. Shepherd's map would be bad maps according to this standard.

Before geographical discourse became saturated with poststructuralism, there was a single source, the article 'Maps in Literature,' written by the husband and wife team of Phillip and Juliana Muehrcke, that valued maps as 'eloquent fictions' (338). The Muehrckes begin their article by noting that 'popular writers' have long been 'fascinated' by 'the essence of maps' (317). Tracing a history of map loving writers including Cervantes, Joseph Conrad, William Faulker, Mark Twain, and the obligatory Stevenson and Tolkien, the Muehrckes assert that 'such observations [of the gap between map and reality] by [popular] authors offer the map maker valuable insights into the point of view of the map user, who is disassociated from the actual mapping process' (317). Here, geography attests to the value for cartography of maps that are inevitably false, inaccurate, subjective, symbolic, and ideological because they tell us something about the motives of 'map users,' or readers. Popular writers' explorations of these traditionally 'negative' map values suggest they are the kind of imaginative readers who, like the Muehrckes, might delight in Lewis Carroll's parody in Sylvie and Bruno Concluded of a people who make a map 'on the scale of $a$ mile to the mile' (qtd. in Muehrcke and Muehrcke 319). The Mueherckes conclude from this piece of nineteenth-century children's fiction that, 'Since the exact duplication of a geographical setting is impossible, a map is actually a metaphor' (319). The geographers note that 'A map is both more and less than itself, depending on who reads it' (320; emphasis mine). The map becomes a supplement that points the reader outside the map and outside the accompanying verbal text. Pavlik agrees, writing 'the space of the map is always more than what is contained within its arbitrary borders' (37). Comparing the indeterminate spaces of literary maps to Baudrillard's notion that 'it is "the map that precedes the territory [. . .] that engenders the territory," (qtd. in Pavlik 38), Pavlik claims on behalf of literary maps the power to offer a "visual chronotrope of the possibilities of spatiality that are not always described verbally by the narrative itself. Literary maps are the territory in the minds of its readers' (38). In either case, Pavlik's or the Mueherckes's, it is the reader who determines the meaning of the map, even as the reader's access to the map is organized by the physical book and culturally specific conventions of reading. 


\section{Map Effects}

15

Readers who begin their excursion into Portrait of a Village or Winnie the Pooh by examining the endpaper maps will experience similar kinds of map effects, functions of the material conditions attending each book's printing and publication. Even those readers who pass over the endpaper maps on a first approach will feel the map effects as soon as they begin reading. For doesn't each map invite readers to come back, to consult its spaces as they pass time in the fantasy worlds of the narratives? If readers follow up on this invitation, they are engaged in an active pursuit of a doubly suspended disbelief. Turning from pages of text to endpapers, type to map, they seek to verify the felt reality of the story that spins out in narrative time against the seen reality of maps contained by spatial borders. In this way endpaper maps seem to guarantee the reality-effects of any story, no matter how fantastic. If we're lost in a story, we can still find our way on the map for maps are ideologically posed to be guarantors of truth. In the words of linguist and folklorist W. F. Nicolaisen, 'maps are inserted as verification, as manipulative devices alleging trustworthiness and solidity, as resourceful aids to the narrating strategist, surveyors of fictitious landscapes within tales of fiction'. (62). Nicolaisen is speaking here of Tolkien's The Hobbit, which begins with 'Thror's Map' and ends with Tolkien's map of Wilderland. The two sets of endpaper maps in The Hobbit create the same kind of map effects for readers of Tolkien's adventure fantasy as are experienced by readers of Young's or Milne's much tamer fantasies of pastoral England. In each case, we read endpaper maps as stable texts on which to pin a moving story, pretending that a representation of a place at one moment in time can substitute for and represent that place for all time.

themselves appear to be formally conservative insofar as they imply that a known and sometimes beloved imaginary world is real, but unlike real worlds, is static, contained, and controlled by the artist who maps it. Not surprisingly, Portrait of a Village announces its conservatism in its first pages: 'history, which is mainly concerned with unpleasant and violent events, has consigned Monk's Norton to centuries of happy obscurity' (12). The industrial revolution only intensified this obscurity, having brought a canal that does not connect the hamlet with the modernizing world, but rather seems to have turned it into a 'self-sufficient, self-centred, and (almost) a self-supporting community' (13). The happy result for readers who enjoy such fantasies is that Monk's Norton 'remains to this day more typical . . . of a kind of life that is fast disappearing. . . than any of its neighbours: a village of un-industrialized England perpetually preserved (as a fly in amber) in its limpid, crystalline matrix of Severnside air' (13). Hassall's map may seem to validate formally the conservative nostalgia of Young's prose, which literary critic Glenn Cavaliero describes as 'supple, rhythmic' 'flowing through everything'-its bland features amounting to nothing less than 'a deception' (88). But the validation of nostalgic feelings inspired by Young's flowing, deceptive prose is not the only map effect of Hassall's endpapers. Many readers will decide to flip back and forth between text and map, map and text, finding on the level of process rather than theme or form that Hassall's endpaper maps are disruptive. Repeatedly losing our place in the text as we verify our place on the map, readers of fictions with endpaper maps learn that such conventional, sentimental books as Milne's and Young's also destabilize the concentrated, front to back reading experience demanded by unillustrated books of type. Endpaper maps make possible a different kind of reading-different from reading books with maps 
in interior pages, different from reading books with pictures, different from reading books with no maps or pictures. The question, then, is 'What meaning does this difference have for our understanding of the relation between the endpaper maps and regions outside of Milne's and Young's books, the countryside and communities of rural England in the interwar period?'

\section{Imagining Rural England}

Historian Malcolm Chase tells us that 'Writing about rural England, and seeing in it all the essential qualities of Englishness, arguably reached a climax in the years 1930-45' (128). Chase and other historians of rural England, including John Lowerson and John Newby, arrive at this conclusion through analysis of diverse genres of English literature, from Flora Thompson's popular rural novels Lark Rise to Candleford to H. J. Massingham's nonfiction essays to the Right Book Club's 1946 selection A Countryman's Creed, to ramble books, Batsford and Shell guidebooks, and to 'an extensive, more technical agricultural literature' (Chase 128).

Whether represented as a playland or wasteland, children's or adults' terrain, rural England meets cosmopolitan England in the interwar years in print media and more specifically, in London-based publishers. Having mastered the technologies of cheap print, these publishers made it possible for readers to buy, not simply borrow, books whose densely illustrated pages urged them to explore on motor and foot the very scenes that so engaged them on paper. Hassall's wood engraving of 'The Stricken Oak' [Figure 7], reproduced beautifully in Heinemann's first edition of Portrait of a Village, no less than a cheap soft-focus photograph, could inspire readers with feelings of longing, nostalgia, and regret over a beautiful but threatened or lost rural landscape and imagined way of life that could only temporarily be satisfied by the pleasures of reading. For historians of the interwar period, what is at stake in understanding representations of the countryside is nothing less than the feeling of reality and the possibility of the feeling's truthful representation. In Lowerson's words, '[For] most writers, and even more for their readers, the countryside had become a symbol of some vague mirage of 'real' life' (277).

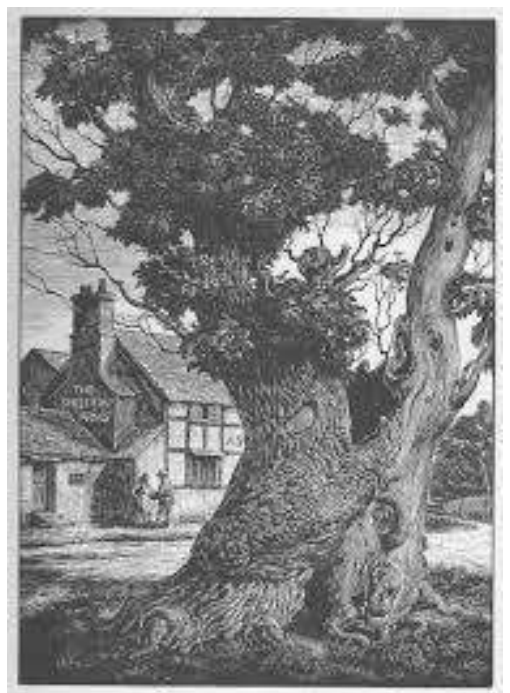

Figure 7: Joan Hassall's "The Stricken Oak," wood engraved frontispiece of Francis Brett Young's Portrait of a Village. Source: https://encrypted-tbn0.gstatic.com/images? q=tbn:ANd9GcRr_rMASjFM7026Pnc4QpGmbQlsdr840a1kxs_C_JQEYcrGSLMO. Accessed 1 December 2015 


\section{'Real' Life} endpaper maps exceed the power of other kinds of countryside literature to symbolize 'some vague mirage of "real" life.' This power emerges out of the unique material shape of books and the way they structure our access to and experience of narrative through map effects. Yet our desires to find in countryside publications 'some vague mirage of "real" life' cannot be understood as exclusively bound to a formal history of book making that only directs us 'inside' books, to their endpapers, illustrations, and narratives. They are also bound to the effects of a national print culture that registered with great intensity and variety the 'outside' social and economic forces impacting rural England during the interwar years. The odd formal kinship between the endpaper maps in Portrait of a Village and Winnie the Pooh represents a broader cultural pattern of borrowing between illustrated media of childhood and adulthood- a pattern that remains largely unacknowledged by scholars of adult literature. Once discovered, this pattern of borrowing appears so pervasive as to support the claim that we will only understand interwar texts of middlebrow regionalism like Francis Brett Young's Portrait of a Village when we study children's literature of the Golden Age-the literature that scholar Humphrey Carpenter summarizes with the names of 'Kingsley, Carroll, MacDonald, Grahame, Potter, Nesbit [and] Barrie, with Milne as a latecomer' (66). This kind of children's literature, almost universally organized around a pastoral fantasy of idealized Englishness, functions as the national or political unconscious of those many interwar texts about the countryside that so concern Chase, Lowerson, and Newby.

In practical terms, a ten year old child who read Winnie the Pooh in 1926 was being trained to enjoy Young's Portrait eleven years later in 1937 when he or she reached the adult age 21. Of course plenty of children would be reading Winnie the Pooh-or having Pooh read to them-for the first time in 1937, introduced to the book by adults who were already enthusiastic readers of Young's rural fantasies. Regardless, it is the history of the everyday experiences of readers once disparaged as middlebrow that will help us recognize the dynamic, mutually reinforcing, and mutually constitutive relations between children's and adults' literature about the countryside. Those relations developed along a two way street, forms travelling from children's to adult books, influencing adult habits of reading just as much as forms travelled from adult to children's books, influencing children's habits of reading.

21 More than ten years after Portrait of a Village was published and more than twenty years after Winnie the Pooh appeared, children's author, A. A. Milne, and adults' illustrator, Joan Hassall, found themselves working together on the same book project. Their pamphlet Books for Children was published by the National Book League and printed by Cambridge University Press in 1948, when paper was still rationed and new books still scarce. Books for Children was part of a series that included titles like C. Day Lewis's Enjoying Poetry, W. P. Matthew's Home Handyman, Elspeth Huxley's Colonies, and A. G. Street's Farming. Joan Hassall designed all of these books, her delicate wood engravings adorning covers and title pages. Cheap, ephemeral, but beautiful, the National Book League pamphlets came out of a second postwar period of bewildering social change. In Books for Children, Milne describes children's literature as a steadying source of adult values: Golden Age children's classics with their symbolic gardens in which 'all will be well once more' are preparations 
for adult 'habit[s] of good reading' (Carpenter 58, Milne 6). In Milne's formulation, children's literature is the chronological basis of adult reading; in this paper, it is the cultural unconscious, shaping readerly desires and anxieties that deeply impact middlebrow culture in its interwar preoccupation with rural regions of England. Either way, the shared forms of the endpaper maps of Portrait of a Village and Winnie the Pooh imply that in addition to analyzing histories of urban print culture, popular reading, and agricultural trends, we need to add analysis of the material forms of books to our middlebrow studies of interwar Anglo-American fiction. Combining art and literary history, we can start with shared knowledge about relations between different kinds of illustrations, book designs, and narratives in order to explore how specific forms and historically determined fantasies of region contribute to middlebrow culture.

\section{Note}

I am indebted to my colleague at Monmouth University, Karen Schmelzkopf, cultural geographer and long-time friend, for providing the initial reading list of geographical sources consulted for this paper.

\section{BIBLIOGRAPHY}

Bluemel, Kristin. 'Illustrating Mary Poppins: Visual Culture and the Middlebrow.' Middlebrow Literary Cultures: The Battle of the Brows, 1920-1960. Ed. Erica Brown and Mary Grover. New York: Palgrave Macmillan, 2012. 187-201.

Brassley, Paul. 'British Farming between the Wars.' The English Countryside between the Wars: Regeneration or Decline? Ed. Paul Brassley, Jeremy Burchardt, and Lynne Thompson. Woodbridge, Suffolk: Boydell P, 2006. 187-99.

Carpenter, Humphrey. 'The First Golden Age.' Children's Literature: Approaches and Territories. Ed. Janet Maybin and Nicola J Watson. London and New York: Palgrave Macmillan for the Open University, 2009. 56-70.

Cavaliero, Glen. The Rural Tradition in the English Novel 1900-1939. Totowa, NJ: Rowman and Littlefield, 1977.

Cep, Casey N. 'The Allure of the Map.' New Yorker 22 Jan. 2014. No pagination. Web. 20 June 2015. Chase, Malcolm. 'This Is No Claptrap: This Is Our Heritage.' The Imagined Past: History and Nostalgia. Ed. Christopher Shaw and Malcolm Chase. Manchester: Manchester UP, 1989. 128-46.

Grahame, Kenneth. The Wind in the Willows. 1908. New York: Scribner, 1933.

Grover, Mary and Erica Brown, eds. Middlebrow Literary Cultures: The Battle of the Brows, 1920-1960. New York: Palgrave Macmillan, 2012.

Hammill, Faye. Women, Celebrity, and Literary Culture between the Wars. Austin: U of Texas P, 2007.

Harbison, Robert. Eccentric Spaces. 1977. Cambridge: MIT P, 2000. 
Harley, J. B. 'Maps, Knowledge, and Power.' The Iconography of Landscape. Ed. Denis Cosgrove and Stephen Daniels. Cambridge: Cambridge UP, 1988.

Honeyman, Susan E. 'Childhood Bound: In Gardens, Maps, and Pictures' Mosaic 34.2 (2001): 117+. Literature Resource Center. Web. 18 December 2013.

Humble, Nicola. The Feminine Middlebrow Novel, 1920s to 1950s:Class, Domesticity and Bohemianism. Oxford: Oxford UP, 2001.

Hunt, Peter. 'Landscapes and Journeys, Metaphors and Maps: The Distinctive Feature of English Fantasy. Children's Literature Association Quarterly. 12.1 (1987): 11-14. Project Muse. Web. 18 December 2013.

Light, Alison. Forever England: Femininity, Literature and Conservatism between the Wars. New York: Routledge, 1991.

Lowerson, John. 'Battles for the Countryside.' Class, Culture, and Social Change: A New View of the 1930s. Ed. Frank Gloversmith. Atlantic Highlands, NJ: Humanities P, 1980. 258-80.

Macdonald, Kate, ed. The Masculine Middlebrow, 1880-1950: What Mr. Miniver Read. New York: Palgrave Macmillan, 2011.

McAleer, Joseph. Popular Reading and Publishing in Britain, 1914-1950. Oxford: Clarendon P, 1992.

Milne, A. A. Books for Children: A Reader's Guide. Wood engravings by Joan Hassall. London: National Book League, 1948.

---. Winnie-the-Pooh. Decorations by E. H. Shepard. New York: E. P. Dutton, 1926.

Muehrcke, Phillip and Juliana Muehrcke. 'Maps in Literature.' The Geographical Review 64.3 (1974): 317-38.

Newby, Howard. Country Life: A Social History of Rural England. London: Weidenfeld and Nicolson, 1987.

Nicolaisen, W. F. H. 'Maps of Fiction: The Cargography of the Landscape of the Mind.' Onomastica Canadiana. 72.2 (1990): 57-68.

Pavlik, Anthony. 'A Special Kind of Reading Game': Maps in Children's Literature.' International Research in Children's Literature. 3.1 (2010): 28-43.

Piatti, Barbara, Hans Rudolf Bar, Anne-Kathrin Reuschel, Lorenz Hurni and William Cartwright. 'Mapping Literature: Towards a Geography of Fiction.' Cartography and Art. Ed. William Cartwright, Georg Gartner, and Antje Lehn. Berlin: Springer-Verlag, 2010. 177-92.

Ransome, Arthur. Swallows and Amazons. 1930. Boston: David R. Godine, 1985.

Robinson, Arthur H. and Barbara Bartz Petchenik. The Nature of Maps: Essays toward Understanding Maps and Mapping. Chicago: U of Chicago P, 1976.

Stevenson, Robert Louis. Treasure Island. 1883. Oxford: Oxford UP, 1985.

Tolkien, J. R. R. The Hobbit or, There and Back Again. 1937. New York: Houghton Mifflin Co., 2001.

Wood, Denis. 'The Power of Maps.' Scientific American May 1993: 88-94.

Young, Francis Brett. Portrait of a Village. Engravings on wood by Joan Hassall. London:

Heinemann, 1937. New York: Reynal and Hitchcock, 1938. 


\section{NOTES}

1. I am grateful to Kate Macdonald for inviting me to deliver a version of this paper at the January 2014 conference on European Middlebrow held in Brussels at the Royal Flemish Academy for the Humanities and Art.

2. This definition is Arthur Robinson and Barbara Bartz Petchenik's, appearing in the introductory chapter of The Nature of Maps (1976), the first book to propose a general theory of cartography (15).

3. Faye Hammill's Women, Celebrity, and Literary Culture between the Wars (2007) was among the first scholarly studies to attempt a 'recuperation of the [Anglo-American] middlebrow' (7), challenging critics to reject the limiting definitions advanced by interwar literary elites and instead find an 'affirmative standpoint for writers who were not wholly aligned with either high modernism or popular culture' (6).

4. See Erica Brown and Mary Grover, Kate Macdonald, Nicola Humble, Alison Light, and especially Hammill. The latter emphasizes the visual style of middlebrow narratives which she relates to the visual images used in the marketing of middlebrow books and celebrity authors. Her research on L. M. Montgomery's best-selling Anne of Green Gables children's books is central to her formulation of a newly valued middlebrow critical category.

5. Joseph McAleer's authoritative Popular Reading and Publishing in Britain 1914-1950 concludes that members of the 'new reading public' (lower-middle and working-class readers) in the years following World War I did not distinguish between books and magazines and were drawn to the “'look" of a book or a sensational title' (71). This led to conformity of style and genre, with 'light fiction' dominating the popular market. He reports on concerns of the period that child readers, vastly expanded in numbers, were 'reflecting too closely the low-brow tastes of their parents' (133).

6. See my 'Illustrating Mary Poppins,' which draws upon visual-verbal theories of picture book scholar Perry Nodelman and media theorist and art historian W. J. T. Mitchell to argue that verbal texts that include limited graphic representation and thus assume the mixed media form of children's chapter books may disturb more forcefully than other kinds of literature modernist ideologies extolling verbal purity.

7. 'Mapper' is the 'all-inclusive' term Robinson and Petchenik use to designate 'all who increase their spatial knowledge of the milieu by any sort of sensory input' (19). Anthony Pavlik notes that literary maps typically represent multiple and contradictory perspectives and scales (35).

\section{ABSTRACTS}

This article argues that endpaper maps in children's and adult's fictions, read in terms of the material contexts of the novels they illustrate and their specific historical contexts, point to new ways of conceiving and organizing middlebrow studies in relation to nation and region. It urges scholars interested in developing middlebrow studies beyond Anglophone cultures to pay greater attention to the materials and material cultures of the book. Based on a case study of endpaper maps by the English wood engraver Joan Hassall and illustrator E. H. Shepard, in novels by Francis Brett Young and A. A. Milne, respectively, it seeks to answer these questions: What kinds 
of illustrations, papers, endpapers, and designs, conveyed through what kinds of varied artistic, industrial, and commercial processes, are required for consumers in diverse regions to behold an object that they recognize as a "middlebrow book"? How are these materials and processes distinguished by region and more importantly, how do these materials and processes themselves produce ideologies of region? In short, how do book materials and processes create different kinds of regional middlebrows?

\section{INDEX}

Mots-clés: literary maps, middlebrow fiction, imaginary geographies, illustration, wood engraving, cultural hierarchies, children's literature, regional literature

\section{AUTHOR}

\section{KRISTIN BLUEMEL}

Monmouth University

Kristin Bluemel is Professor of English and Wayne D. McMurray Endowed Chair of the Humanities at Monmouth University in New Jersey, USA. She is author of George Orwell and the Radical Eccentrics : Intermodernism in Literary London (2004) and editor of Intermodernism : Literary Culture in Mid-Twentieth-Century Britain (2009), among other works. Her most recent publication is 'The Saltire Chapbooks, Twentieth-Century Wood Engraving, and “A Vast New Public of Readers," published in The Journal of the Edinburgh Bibliographical Society. Her work in progress is a volume of essays, Rural Modernity in Britain : A Critical Intervention, which she is co-editing with Michael McCluskey for Edinburgh University Press 